Cahiers de recherches médiévales

Journal of medieval studies

$18 \mid 2009$

Le système d'enseignement occidental $\left(\mathrm{XI}^{\mathrm{e}}-\left.\mathrm{XV}\right|^{\mathrm{e}}\right.$ siècle)

\title{
Introduction
}

\section{Bruno Méniel}

\section{OpenEdition}

Journals

Édition électronique

URL : https://journals.openedition.org/crm/11709

DOI : $10.4000 / \mathrm{crm} .11709$

ISSN : 1955-2424

Éditeur

Honoré Champion

\section{Édition imprimée}

Date de publication : 20 novembre 2009

Pagination : 265-266

ISSN : $1272-9752$

\section{Référence électronique}

Bruno Méniel, «Introduction », Cahiers de recherches médiévales [En ligne], 18 | 2009, mis en ligne le 15 décembre 2012, consulté le 15 décembre 2022. URL : http://journals.openedition.org/crm/11709 ; DOI : https://doi.org/10.4000/crm. 11709 


\section{RM}

\section{Hors-la-loi}

Les personnages des œuvres littéraires entrent souvent en conflit avec le droit. Les uns se situent en deçà de la loi : les aigrefins qui prospèrent dans la farce et la nouvelle suscitent l'intérêt parce qu'ils ont l'audace et le courage d'enfreindre la législation. D'autres personnages se situent au-delà : plaçant l'amour, le goût du pouvoir, l'éthique personnelle, plus haut que le respect des règles sociales, ils sapent par leur comportement l'autorité du roi ou du juge.

Par l'importance qu'elle accorde aux barons révoltés, la littérature épique médiévale tend à privilégier le second schéma. Philippe Haugeard note cependant que, pour qu'un révolté se comporte en hors-la-loi, il faudrait que la loi soit véritablement présente à son esprit. Il montre, à partir de Girart de Roussillon, que dans la société féodale du XII ${ }^{\mathrm{e}}$ siècle, la notion de droit renvoie moins à un dispositif de lois et de coutumes qu'à des impératifs moraux de probité et d'équité et, somme toute, aux valeurs de la noblesse. Néanmoins, l'axiologie d'une classe sociale, travaillée par les passions, n'a pas la froideur, la rigueur, l'intangibilité de la loi, ni non plus son pouvoir de contrainte. Faute d'une norme qui permettrait d'arbitrer les conflits, aucune limite n'est imposée à la volonté de puissance de Girart et de Charles, et la discorde s'installe.

L'ascension du personnage du révolté dans la poésie du XII ${ }^{\mathrm{e}}$ siècle pourrait bien correspondre à ce que Dominique Boutet définit comme «une crise de la représentation de la royauté ${ }^{\star} »$. L'Histoire de Fouke Fitz-Warin, qui date du XIV siècle, raconte l'opposition d'un baron vertueux à un roi inique et vindicatif, Johan, figure littéraire de Jean-sans-Terre : le hors-la-loi incarne la justice; il ne rend plus compte de ses actes à son roi, mais à Dieu. Myriam White-Le Goff révèle la question que ce texte soulève: un roi, lorsqu'il obéit à ses passions au lieu de gouverner dans l'intérêt commun, reste-t-il fondé à légiférer?

Parce que les Nouvelles Récréations et Joyeux Devis de Bonaventure Des Périers ont une tonalité facétieuse, on pourrait considérer qu'elles vérifient le premier schéma. Pour Jean-Claude Arnould, au contraire, elles mettent en évidence, par delà les dysfonctionnements de l'appareil judiciaire, l'incapacité de la loi à produire une justice authentique. La fiction devient alors un espace où, au mépris de la législation, d'autres conduites s'inventent, et où le rire offre une compensation aux victimes des prévôts et des juges. C'est le narrateur qui, en dernier lieu, oppose à la fausse justice des institutions le discours vrai, mais obscur, voilé, ironique, secret, de la loi éthique.

On l'aura compris, ce cahier thématique, qui s'inscrit dans le projet ANR Juslittera visant à étudier les rapports entre Droit et Littérature, est l'occasion de sonder la complexité des attitudes face à la loi, entre Moyen Âge et Renaissance. La difficulté de l'entreprise pourrait tenir à ce singulier: la loi. Les milieux qu'explorent les œuvres étudiées ne sont pas sans foi ni loi, mais ce sont des univers

${ }^{1}$ D. Boutet, Charlemagne et Arthur ou le roi imaginaire, Paris, Champion, 1992, p. 609.

Cahiers de Recherches Médiévales, 18, 2009 
où les normes se superposent et s'enchevêtrent, qu'elles soient juridiques, sociologiques ou éthiques, formulée ou implicites. Et, pour démêler cet écheveau, la littérature n'est pas inutile.

Bruno Méniel CELAM - Université de Rennes 2

ANR Juslittera 